\title{
Genome-wide Association Study of Pulmonary Function in Europeans and Africans from the UK Biobank Identifies Distinct Variants
}

\author{
Musalula Sinkala1థ, Samar S. M. Elsheikh²థ, Mamana Mbiyavanga1', Joshua
}

Cullinan ${ }^{1}$, Nicola J. Mulder ${ }^{1}$

1, University of Cape Town, Faculty of Health Sciences, Institute of Infectious Disease and Molecular Medicine, Computational Biology Division, Anzio Rd, Observatory, 7925, Cape Town, South Africa

2, Pharmacogenetics Research Clinic, Campbell Family Mental Health Research Institute, Centre for Addiction and Mental Health,

Toronto, ON, Canada

$\phi$, Contributed equally.

\section{Correspondence}

musalula.sinkala@uct.ac.za 
medRxiv preprint doi: https://doi.org/10.1101/2022.01.07.22268836; this version posted January 8, 2022. The copyright holder for this preprint (which was not certified by peer review) is the author/funder, who has granted medRxiv a license to display the preprint in perpetuity.

It is made available under a CC-BY-NC 4.0 International license .

\section{Abstract}

Pulmonary function is an indicator of well-being, and pulmonary pathologies are the third major cause of death worldwide. FEV1, FVC, and PEF are quantitively used to assess pulmonary function. We conducted a genome-wide association analysis of pulmonary function in 383,471 individuals of European and 5,978 African descent represented in the UK Biobank. Here, we report 817 variants in Europeans and 3 in Africans associated ( $p$-values $<5 \times 10^{-8}$ ) with three pulmonary function parameters; FEV1, FVC and PEF. In addition to 377 variants in Europeans previously reported to be associated with phenotypes related to pulmonary function, we identified 330 novel loci, including an ISX intergenic variant rs369476290 on chromosome 22 in Africans and a KDM2A intron variant rs12790261 on chromosome 11 in Europeans. Remarkably, we find no shared variants among Africans and Europeans. Enrichment analyses of variants separately for each ancestry background revealed significant enrichment for terms related to pulmonary phenotypes in Europeans but not Africans. Further analysis of studies of pulmonary phenotypes revealed individuals of European background are disproportionally overrepresented in datasets compared to Africans, with the gap widening over the past five years. Our findings offer a better understanding of the different variants that modify pulmonary function in Africans and Europeans, a significant finding for future GWAS studies and medicine.

\section{Introduction}

Pulmonary function measures using the spirometer are indicators of respiratory health and predict morbidity and mortality ${ }^{1,2}$. These parameters, which include the force expiratory volume in 1-second (FEV1), forced vital capacity (FVC), and peak expiratory capacity (PEF), vary significantly among populations of different ancestry backgrounds $^{3}$ and show strong evidence of genetic and environmental influences ${ }^{2,4}$.

During the last decade, large-scale genome-wide association studies (GWASs) have used various pulmonary parameters to evaluate the genomic loci associated with pulmonary function and related traits that have yielded hundreds of associated variants ${ }^{5-10}$. These and other studies indicate that genomic loci associated with pulmonary function overlap with chronic obstructive pulmonary disease (COPD), asthma, pulmonary fibrosis, lung cancer, and other pulmonary phenotypes ${ }^{1,8-10}$. A recent GWAS based on the UK Biobank cohort $(N=50,008)$, including heavy smokers and never smokers, identified six loci associated with low FEV1 ${ }^{10}$. Another study in individuals $(\mathrm{N}=48,943)$ sampled from the extremes of pulmonary function distribution in UK Biobank identified 95 variants strongly associated with COPD susceptibility 8 . Importantly, these previous studies have applied the analyses on a selected population group of primarily European ancestry.

The UK Biobank cohort provides data on over 500,000 individuals that offers new prospects to identify variants associated with pulmonary function among Europeans and Africans using GWAS approaches by allowing for large-scale comparisons of lung function parameters ${ }^{11}$. Furthermore, by integrating the genetic association of FEV1, PEF, and FVC, a list of shared loci that collectively modify pulmonary function could be identified. We hypothesise that different genetic variants are associated with 
medRxiv preprint doi: https://doi.org/10.1101/2022.01.07.22268836; this version posted January 8, 2022. The copyright holder for this preprint (which was not certified by peer review) is the author/funder, who has granted medRxiv a license to display the preprint in perpetuity.

It is made available under a CC-BY-NC 4.0 International license .

pulmonary function in Africans. Thus, their identification will provide additional information relevant to understanding pulmonary function in physiology and disease in district populations. However, to our knowledge, no GWAS study has been performed to compare the SNPs associated with the full range of FEV1, FVC and PEF parameters across the entire UK Biobank cohort and separately among Africans and Europeans.

Here, we compare variations in pulmonary function parameters among individuals of African and European ancestry represented in the UK biobank. First, we used the genome-wide associated summary statistics for three UK Biobank defined continuous pulmonary function parameters; FEV1, FVC, and PEF. Then, we conducted further analyses to identify genes, regions, and gene sets associated with each pulmonary phenotype. Furthermore, we evaluate the candidate phenotype loci in relation to published GWAS results. Overall, this approach allows us to report credible loci associated with pulmonary function among Africans and Europeans, which were enriched across many plausible genes and gene sets involved in pulmonary function or related phenotypes.

\section{Results}

\section{UK Biobank pulmonary function demographics}

There were 389,449 participants comprising of Europeans $(\mathrm{N}=383,471)$ and Africans $(\mathrm{N}=5,978)$. The mean age of participants at recruitment was 56.8 (standard deviation $[\mathrm{Std}]=8.0)$ years and $51($ Std $=7.9)$ years for the Europeans and Africans, respectively.

\section{Lung function parameters vary between individuals of Europeans and African ancestry}

We assessed the mean FVC, FEV1, and PEF between Europeans $(\mathrm{N}=383,471)$ and Africans $(N=5,978)$ represented in the UK Biobank datasets. We found that the mean FVC was significantly higher in the Europeans (mean $=3.73 \mathrm{~L}$ ) compared to the Africans (mean $=2.95 \mathrm{~L}$ ), (Welch test: $t=48.35, \mathrm{p}<1 \times 10^{-320}$; Figure 1a). Furthermore, we found that the FEV1 and the PEF were both significantly higher in Europeans (mean FEV1 $=2.82 \mathrm{~L}$, mean PEF $=389.6 \mathrm{~L} / \mathrm{min}$ ) than those measured in the Africans (mean FEV1 $=2.28 \mathrm{~L}$, mean PEF $=332.7 \mathrm{~L} / \mathrm{min}$ ), FEV1; $t=42.60, \mathrm{p}=$ $1.0 \times 10^{-291}$ (Figure $1 \mathrm{~b}$ ) and PEV; $t=24.06, p=1.7 \times 10^{-107}$; Figure $1 \mathrm{c}$.

Previous studies show that the FVC, FEV1, and PEF vary with age, body mass index (BMI), and height of the individuals ${ }^{12-15}$. Here, also, we found that FVC, FEV1, and PEF tend to reduce as the age and BMI of the individuals' increases, and all three parameters increase alongside the height of the individuals (Figure $1 \mathrm{~d}$ and Supplementary Figure 1a-1i). Furthermore, we observed that the FVC/FEV1 levels are conversely higher in Africans than Europeans across the BMI percentiles (Figure 1e). 
medRxiv preprint doi: https://doi.org/10.1101/2022.01.07.22268836; this version posted January 8, 2022. The copyright holder for this preprint (which was not certified by peer review) is the author/funder, who has granted medRxiv a license to display the preprint in perpetuity.

It is made available under a CC-BY-NC 4.0 International license .
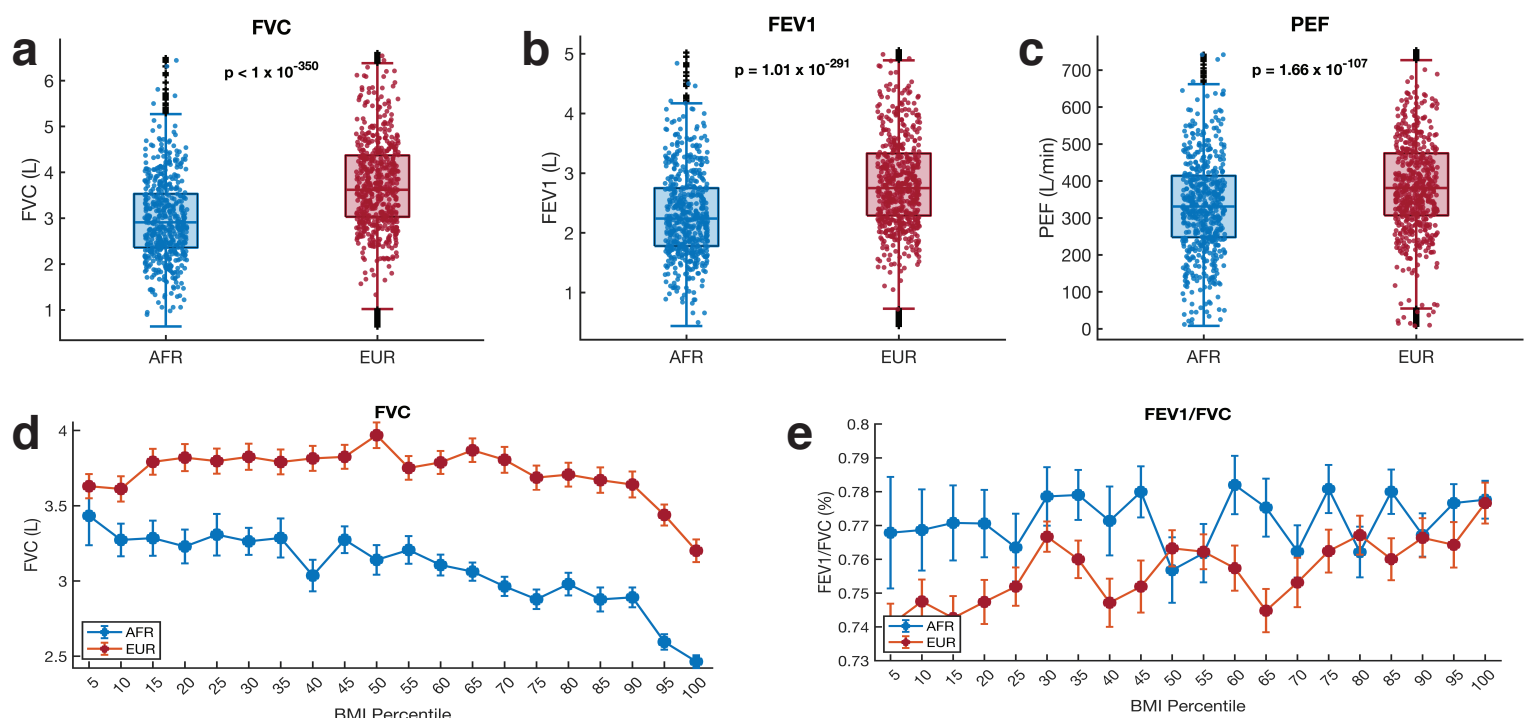

Figure 1: Comparison of the pulmonary function parameter among Africans and Europeans for (a) FEV1, (b) FVC, and (c) PEF. The boxplots indicate the distribution of each test parameter in each group. The $p$-values shown for each comparison were calculated from Welch's $t$-test. On each box, the central mark indicates the median, and the left and right edges of the box indicate the 25th and 75th percentiles, respectively. The whiskers extend to the most extreme data points not considered outliers, and the outliers are plotted individually using the ' + ' symbol. To make the visualisation clearer, the filled circle mark showing the distribution only include 1000 randomly sampled point from the entire samples size of each group. Error bars showing the variation in (d) FVC and (e) FEV1/FVC across BMI percentiles among Africans and Europeans. The middle point indicated the mean FVC or FEV1/FVC, and the error bars indicate the standard error of the mean at the particular BMI percentile.

\section{Genetic variant associated with FVC, FEV1 and PEF among Europeans and} Africans

Since the FVC, FEV1 and PEF values were significantly higher in Europeans than in Africans. We presumed that a genome-wide association analysis would identify the genetic variants associated with each of these pulmonary function parameters in each group. Therefore, we collected the GWAS summary statistics for each pulmonary function parameter within each ethnic group (see methods sections). The total number of significant variants (including those in linkage disequilibrium) identified for each pulmonary function parameter is shown in Supplementary Figures $2 \mathrm{a}, 2 \mathrm{~b}$ and $2 \mathrm{c}$.

We identified 310 genetic variants significantly associated ( $p$-values $<5 \times 10^{-8}$ and causal probability $>0.1$; see methods section) with $F V C$ in Europeans and 2 significant associations in Africans (Figure 2a and Figure 2b). For FEV1, we found 308 significant SNP associations in Europeans and 1 in Africans (Figure 2c and Figure 2d). Furthermore, for PEF, we found 374 significant associations in Europeans and none (0) in Africans (Figure 2e and 2f). Surprisingly, we found that the significant SNPs associated with FVC, FEV1 and PEF for each group were unique (Figure 2g, Figure 2h, Figure 2i and Supplementary File 1).

We compared the 817 unique SNPs in Europeans with the 3 SNPs in Africans significantly associated with the three pulmonary function parameters and found no 
medRxiv preprint doi: https://doi.org/10.1101/2022.01.07.22268836; this version posted January 8, 2022. The copyright holder for this preprint (which was not certified by peer review) is the author/funder, who has granted medRxiv a license to display the preprint in perpetuity.

It is made available under a CC-BY-NC 4.0 International license .

common variants between the two sets. Conversely, we found that 236 SNPs were associated with FVC and FEV1 in the Europeans (Figure 2k). However, there was no overlap in the associated SNPs among Africans (Figure 2j).

Since the SNPs significantly associated with pulmonary function were unique for Europeans and Africans, we next relaxed the GWAS significance threshold to a suggestive cutoff $p$-value ${ }^{16}$ of $1 \times 10^{-6}$. Then, we compared the significant SNPs in Europeans and Africans for FVC, FEV1 and PEF. Using a less stringent significance threshold, we still found no common SNPs among Africans and Europeans for all three pulmonary function parameters (Supplementary Figure $2 \mathrm{~d}, 2 \mathrm{e}$ and $2 \mathrm{f}$ ).

a

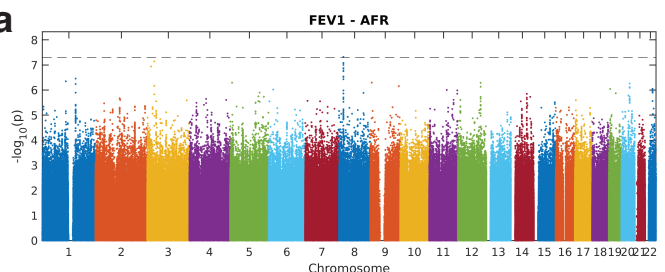

C

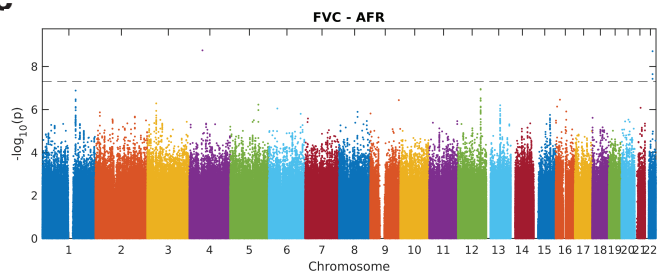

e



f

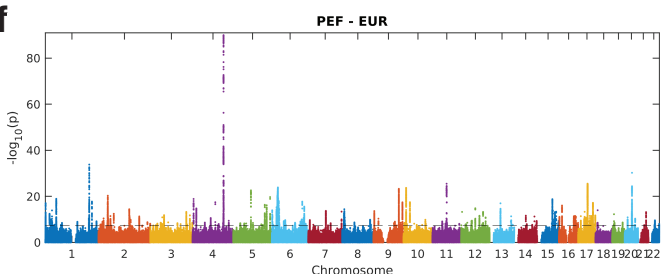

b

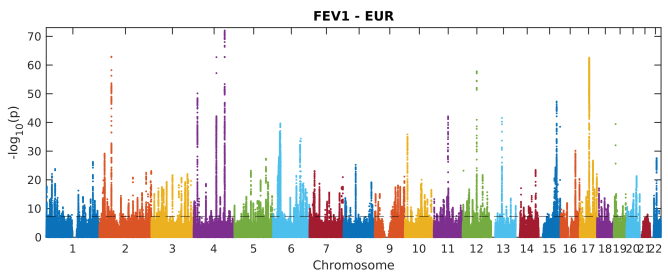

d

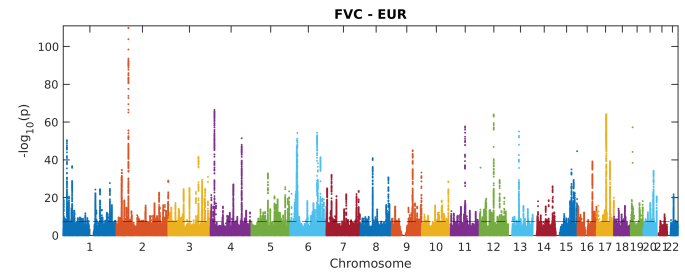

g

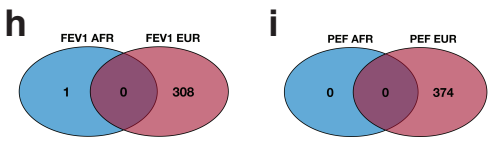

j



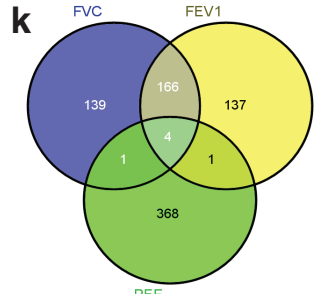

Figure 2: Manhattan plots of the SNPs associated with (a) FEV1 in African and (b) FEV1 in Europeans, (c) FVC in African and (d) FVC in Europeans, and (e) PEF in African and (f) PEF in Europeans for each chromosome. The Venn diagrams show the overlap among the significant causal SNPs associated with (g), FVC (h), PEF, and (i) FEV1 in Africans and Europeans. The distribution of genetic variants associated with three pulmonary function parameters among the (j) Africans and (k) Europeans. Refer to Supplementary File 1 for details concerning individual SNPs and their frequencies among Africans and Europeans.

We compared the minor allele frequency of SNPs in the UK Biobank between Europeans and Africans for the combined 820 SNPs (817 in Europeans plus 3 in Africans) associated with pulmonary function. We found that 788 out of 820 SNPs 
medRxiv preprint doi: https://doi.org/10.1101/2022.01.07.22268836; this version posted January 8, 2022. The copyright holder for this preprint (which was not certified by peer review) is the author/funder, who has granted medRxiv a license to display the preprint in perpetuity.

It is made available under a CC-BY-NC 4.0 International license.

differed significantly in their frequency among the African and Europeans (Supplementary File 2). The top-three variants that exhibited the most significant higher frequencies in Europeans compared to Africans were rs2042395 (frequency in $E U R=0.77$, in AFR $=0.19$, Fisher test $p$-values $\left.=4.94 \times 10^{-323}\right)$, rs3748400 $(E U R=$ $\left.0.78, A F R=0.19, p=6.92 \times 10^{-323}\right)$, rs8045843 (EUR $=0.78, A F R=0.17, p=8.89 x$ $10^{-323}$ ), see Supplementary File 2 and Supplementary Figure $2 \mathrm{~g}$. Interestingly, the variants rs2042395 and rs8045843 have been previously found to be associated with Well-being spectrum ${ }^{17}$ and Sensitivity to environmental stress and adversity ${ }^{18}$ respectively, in individuals of European ancestry. Conversely, the top variants with higher frequency in Africans compared to Europeans were rs143384 (EUR $=0.40$ and $\left.\mathrm{AFR}=0.92, \mathrm{p}=2.0 \times 10^{-323}\right), \mathrm{rs3133084}\left(\mathrm{EUR}=0.23\right.$ and $\mathrm{AFR}=0.65, \mathrm{p}=8.4 \times 10^{-}$ ${ }^{323}$ ), and $r 57853063$ (EUR $=0.20$ and $\left.A F R=0.60, p=6.4 \times 10^{-323}\right)$, see Supplementary Figure $2 \mathrm{~g}$. Among these, the variant $\mathrm{rs} 143384$ has been reported associated with FVC, lung function, and $\mathrm{PEF}^{19}$, and among anthropometric traits in Europeans ${ }^{20}$.

Altogether, these analyses revealed that different SNPs may be associated with FVC, FEV1 and PEF among Europeans and Africans and that the frequency of these SNPs significantly varies between these populations.

\section{Pathway and GWAS Catalogue enrichments of the SNPS}

For each study population, we assessed the enrichment of GWAS catalog 21 annotation terms of the genes in which the SNPs associated (suggestive cutoff $p$-value of $1 \times 10^{-6}$ ) with lung function occur (see Supplementary File 2).
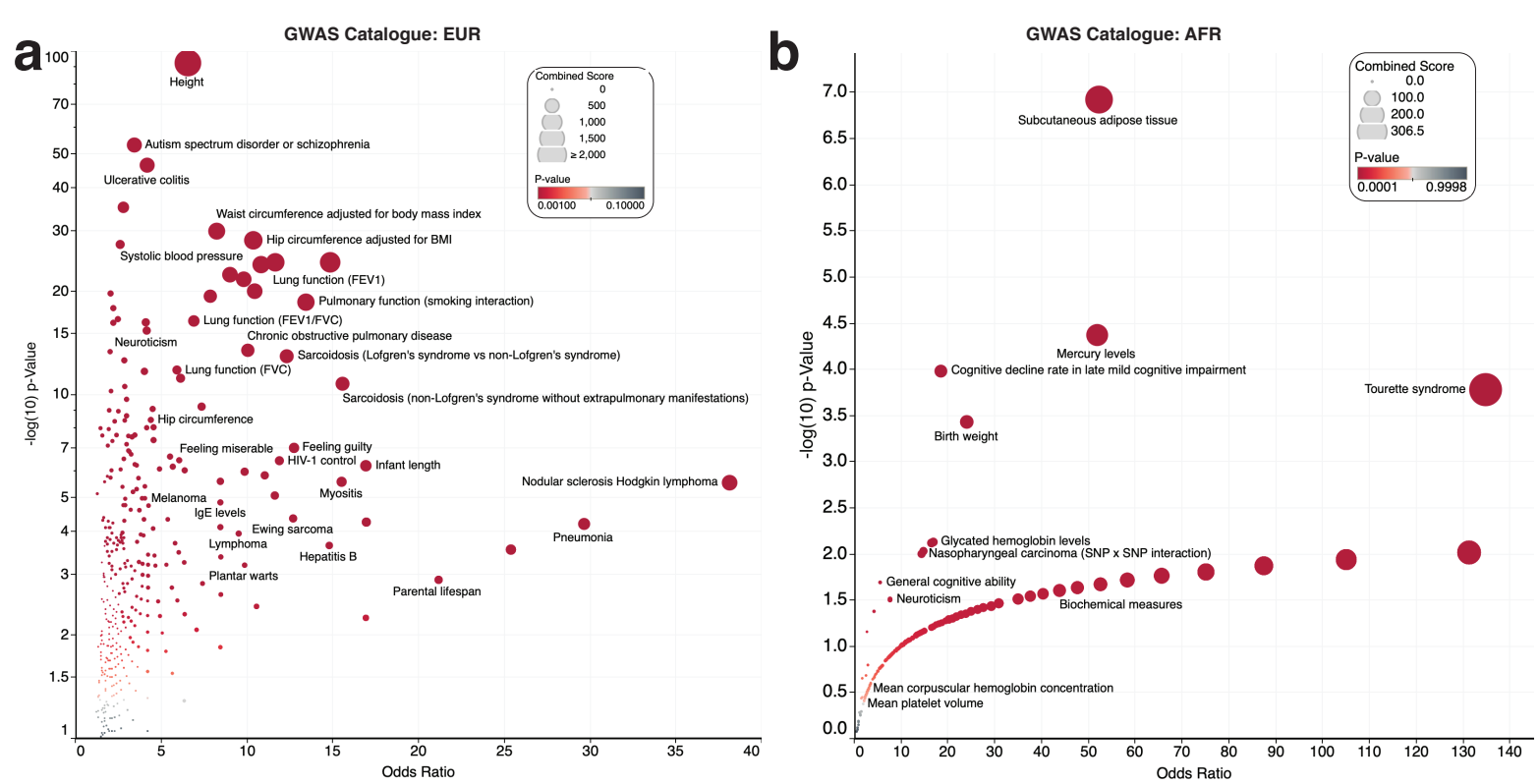

Figure 3: Volcano plots of the GWAS catalogue enrichment analysis for genes in which significant SNPs are located for (a) Europeans and (b) Africans. All four plots show the adjusted p-value on the $y$-axis and the odds ratio of the enrichment score on the $x$-axis. Each circle represents a GWAS catalogue term or Elsevier pathway. The circles are coloured based on the levels of statistical significance, with the redder colours showing a greater degree of significance. Each circle is sized based on the combined enrichment score of the term represented by the circle.

The GWAS catalogue term analyses revealed that in Europeans, the genes were significantly enriched for GWAS terms associated with "Height" (combined score [CS] 
medRxiv preprint doi: https://doi.org/10.1101/2022.01.07.22268836; this version posted January 8, 2022. The copyright holder for this preprint (which was not certified by peer review) is the author/funder, who has granted medRxiv a license to display the preprint in perpetuity.

It is made available under a CC-BY-NC 4.0 International license .

$=1,399$, hypergeometric test; $\left.p=1.06 \times 10^{-93}\right)$, "Lung function (FEV1)" (CS $=8291,5.4$ $\left.\times 10^{-25}\right)$, "Pulmonary function interaction" (CS $\left.=577.5, p=2.33 \times 10^{-19}\right)$ among others (Figure 3a, Supplementary File 3 ). In Africans, we found that the genes were significantly enriched for GWAS terms associated with "Subcutaneous adipose tissue" ( $C S=833.6, p=1.2 \times 10^{-07}$ ), "Birth weight" ( $\left.C S=189.7, p=3.7 \times 10^{-04}\right)$, "Cognitive decline rate in late mild cognitive impairment" $\left(C S=18.6, p=7.3 \times 10^{-04}\right)$, among others (Figure 3b, Supplementary File 3). Overall, these results show that the SNPs identified among Europeans are located in genes known to play roles in many phenotypes, but most notably, those related to pulmonary function or GWAS phenotypes related to pulmonary function. Conversely, the SNPs that we identified associated with pulmonary function among Africans fall within genes that are not enriched for pulmonary function related terms.

\section{Variant spanning loci associated with pulmonary function among Europeans and Africans}

Many of the associated SNPs may simply reflect the linkage disequilibrium structure of the populations ${ }^{22,23}$ (see Supplementary File 4). For example; we found 10 variants associated with FEV1 and FVC in Europeans within loci 12q14.3, upon fine mapping ${ }^{24}$, found that the most likely causal SNP within the loci was rs1351394 (Probabilistic Identification of Causal SNPs [PICS] value $=0.7243$ ), a 3-prime UTR variant located in the gene HMGA2 (Figure 4a). The variant rs1351394 has previously been associated with variations that affect FEV1 capacity, including height ${ }^{25,26}$ and birth length ${ }^{27}$. Furthermore, HMGA2 is involved in lung development ${ }^{28}$.

At the loci 19q13.42, we found that the most likely causal SNP is rs 147110934 (PICS $=0.83$ ) associated with both FEV1 and FVC in Europeans (Figure 4b, also see Supplementary File 4). rs147110934 is a predicted missense variant that falls within the ZNF628 gene. In addition, whilst rs 147110934 has not been previously associated with pulmonary function, we found it is associated with height ${ }^{29}$ and body weight ${ }^{30,31}$, both of which are associated with FVC and FEV1.

Furthermore, we found several SNPs in the loci 9q22.32 associated with pulmonary function (Figure $4 \mathrm{c}$ ). Here, the lead and predicted causal (PICS $=1$ ) variant is rs 16909898 , located in the PTCH1 gene previously identified to modify pulmonary function parameters ${ }^{32,33}$ and height ${ }^{26}$.

In addition, for individuals of African ancestry, at the loci 5q32, the lead SNPs among the four associated with pulmonary function was rs369476290 (PICS $=0.67$ ), an intergenic variant located in the gene, ISX. rs369476290 has not been previously linked to pulmonary function or disease (Figure 4d). 
medRxiv preprint doi: https://doi.org/10.1101/2022.01.07.22268836; this version posted January 8, 2022. The copyright holder for this preprint (which was not certified by peer review) is the author/funder, who has granted medRxiv a license to display the preprint in perpetuity.

It is made available under a CC-BY-NC 4.0 International license.
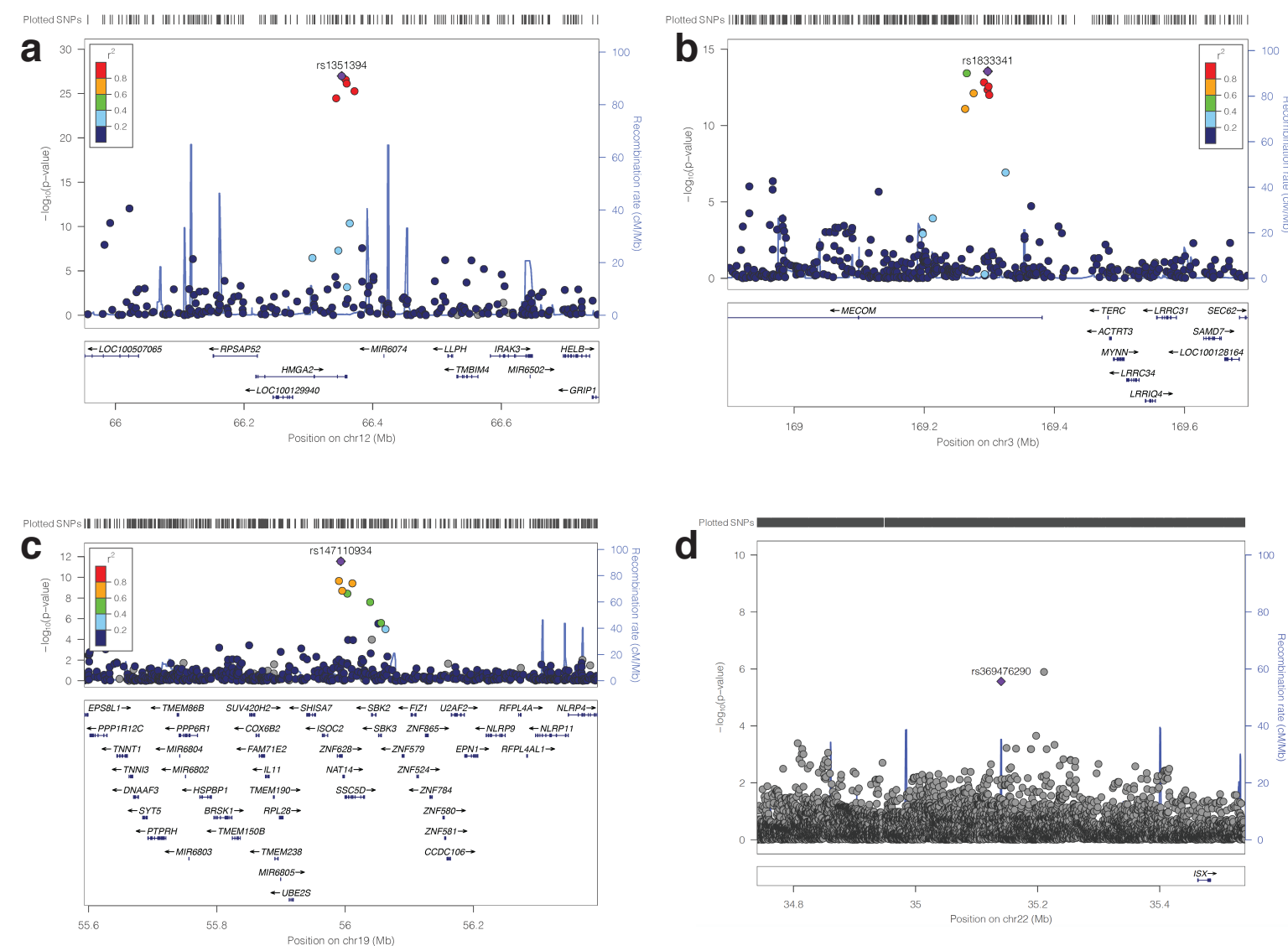

Figure 4: Regional association plots for genome-wide significant pulmonary function loci for the lead SNPs (a) rs1351394 at loci 12q14.3, (b) rs16909898 at 9q22.32, (c) rs147110934 at loci 19q13.42, and (d) rs369476290 on chromosome 22. The genes within the chromosomal loci are shown in the lower panel. The blue line indicates the recombination rate. The filled circles show the position of the SNPS along the region on the $x$-axis and the negative logarithm of the association p-value on the $y$-axis. The lead SNP is shown in purple, and the SNPs within the locus are coloured based on the linkage disequilibrium correlation value (r2) with the lead SNP based on the European HapMap haplotype from the 1000 genome project.

\section{Comparison to variants previously associated with pulmonary function}

Next, we aimed to identify the previously described and novel SNPs among the significant SNPs that were also predicted causal within a particular LD block (see methods section). Here, we grouped the SNPs into four ordinal categories based on confidence: (1) SNPs reported to be associated with pulmonary function, (2) SNPs related to phenotypes correlated to pulmonary function (e.g., height, see Supplementary Figure 1), (3) SNPs that fall within genes reported to be associated with pulmonary function and/or disease, (4) SNPs that are eQTLs in the lung, and (5) the novels SNPs.

Known and novel variants associated with pulmonary function

\begin{tabular}{llllll}
\hline Ethnicity & Pulmonary Function & $\begin{array}{l}\text { Pulmonary Function } \\
\text { Associated Traits }\end{array}$ & Lung Disease Associated & eQTLs & Novel \\
\hline Africans & 0 & 0 & 0 & 0 & 3 \\
Europeans & 85 & 96 & 196 & 3 & 327 \\
\hline
\end{tabular}

Interestingly, we found that among our list, 85 variants in Europeans and none (0) in Africans have been previously associated with pulmonary function (See Table 1 and Supplementary File 4). These include SNPs in the genes PLEKHM1, HMGA2, 
medRxiv preprint doi: https://doi.org/10.1101/2022.01.07.22268836; this version posted January 8, 2022. The copyright holder for this preprint (which was not certified by peer review) is the author/funder, who has granted medRxiv a license to display the preprint in perpetuity.

It is made available under a CC-BY-NC 4.0 International license .

KDM2A, and SYTL2 (Table 2). Likewise, we found that 96 variants in Europeans and none (0) of the variants in African ancestry individuals have previously been associated with a phenotype correlated to pulmonary function (see Supplementary File 4). Furthermore, we found that 196 variants in Europeans and 0 variants in Africans are located within genes associated with various pulmonary function phenotypes and disease, and three SNPs in Europeans and none in Africans were significant eQTLs in the lungs. These three SNPs affect the expression of CAMLG, PHF15 and MLLT6. Finally, we found 327 novel SNPs in Europeans and 3 in Africans associated with pulmonary function; see Supplementary File 4 for the complete list of significant variants and the studies reporting the known variants.

Top significant variants associated with pulmonary function

\begin{tabular}{lllllll}
\hline Variant & Nearest Genes & Ethnicity & Measure & Chrom:Pos & GWAS p & Evidence \\
\hline rs536516159 & LZTS1 & AFR & FEV1 & $8: 20598779$ & $4.8 \times 10$-08 & Novel \\
\hline rs8756 & HMGA2, AC090673.2 & EUR & FEV1 & $12: 66359752$ & $8.4 \times 10^{-58}$ & Pulmonary Function \\
\hline rs55663797 & PLEKHM1 & EUR & FEV1 & $17: 43544379$ & $7.3 \times 10^{-52}$ & Lung Disease Assoc. \\
\hline rs1828591 & HHIP & EUR & FEV1 & $4: 145480780$ & $8.3 \times 10-52$ & Pulmonary Function \\
\hline rs571481915 & LPHN3 & AFR & FVC & $4: 61183218$ & $1.8 \times 10^{-09}$ & Novel \\
\hline rs369476290 & ISX & AFR & FVC & $22: 35140134$ & $2.0 \times 10^{-09}$ & Novel \\
\hline rs8756 & HMGA2 & EUR & FVC & $12: 66359752$ & $1.2 \times 10^{-63}$ & Pulmonary Function \\
\hline rs2696624 & KANSL1 & EUR & FVC & $17: 44326845$ & $1.8 \times 10-62$ & Novel \\
\hline rs7952436 & KDM2A, ADRBK1 & EUR & FVC & $11: 67024534$ & $9.3 \times 10^{-58}$ & Pulmonary Assoc. \\
\hline rs6829956 & HHIP & EUR & PEF & $4: 145440288$ & $1.1 \times 10^{-90}$ & Pulmonary Function \\
\hline rs1342062 & SLC26A9 & EUR & PEF & $1: 205912786$ & $1.6 \times 10^{-34}$ & Lung Disease Assoc. \\
\hline rs143384 & GDF5 & EUR & PEF & $20: 34025756$ & $5.8 \times 10^{-31}$ & Pulmonary Function \\
\hline
\end{tabular}

We focused on the genes in which the novel SNPs associated with pulmonary function among Europeans located to performed enrichment analyses based on the DisGeNET database ${ }^{34}$, Phenotype and Genotype Integrator database (PheGenl) ${ }^{35}$. Here, our DisGeNET analysis revealed that the novel genes are enriched for term related to pulmonary function including "Forced expiratory volume function" $\left(p=9.7 \times 10^{-13}\right)$ and body measures that modify pulmonary function including "Body Height" $\left(p=1.33 \times 10^{-}\right.$ ${ }^{15}$ ), see Supplementary Figure 3. Similarly, our PhenGenl enrichment analysis revealed that the genes are enriched for term pulmonary function terms including Forced Expiratory Volume $\left(p=2 \times 10^{-4}\right)$ and phenotypes associated with pulmonary function including Body Height $\left(p=4.2 \times 10^{-07}\right)$, see Supplementary Figure 3. Overall, these findings show that despites the SNPs being novel among Europeans, the genes within which the SNPs are located are known to be associated with Pulmonary function.

\section{Bias in GWAS studies explains why few SNPs were previously associated with pulmonary function in Africans}

Since none of the SNPs that we identified associated with pulmonary function among Africans have been reported in the literature, we queried the GWAS catalog ${ }^{21}$ for previous studies of pulmonary function or phenotypes related to pulmonary function (such as asthma) across various ancestry backgrounds. We found those studies to be 
medRxiv preprint doi: https://doi.org/10.1101/2022.01.07.22268836; this version posted January 8, 2022. The copyright holder for this preprint (which was not certified by peer review) is the author/funder, who has granted medRxiv a license to display the preprint in perpetuity.

It is made available under a CC-BY-NC 4.0 International license .

significantly biased toward individuals of European ancestry (Figure 5a). Also, despite the number of studies conducted on individuals of African ancestry increasing over the last five years, the gap is widening between the number of studies reported on Europeans compared to Africans during the same time interval (Figure 5a). Overall, among the 235 GWAS studies reported on pulmonary function or phenotypes related to pulmonary function, only eight were conducted on Africans/African Americans. In comparison, we found that 120 studies have been conducted exclusively on individuals of European ancestry (Figure 5b). Furthermore, in the same studies, the cumulative samples size of the Europeans in 2021 (10,633,660 individuals) is approximately 235 times greater than that of the Africans $(45,189$ individuals; see Figure 5c).



b) Africans Europeans Others

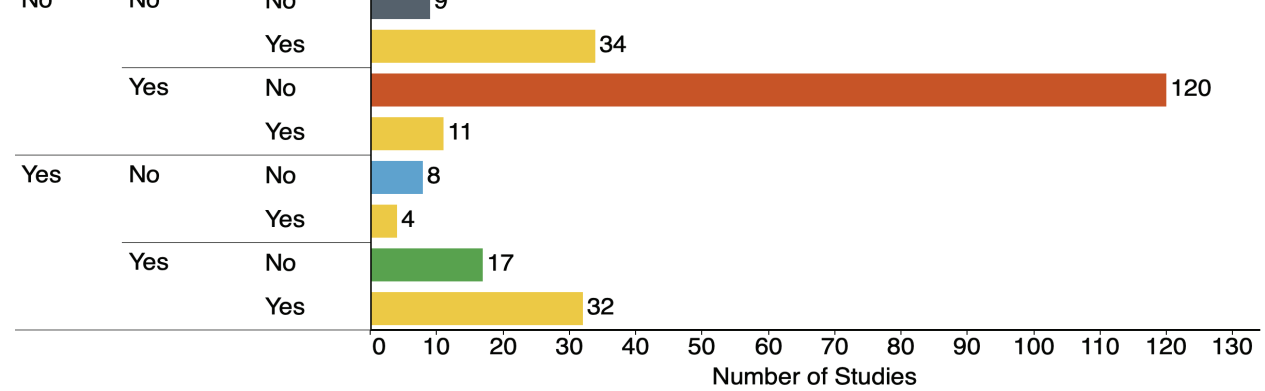

Study Group
Africans Only Europeans and Africans Europeans Only
Not Provided Not Provide
Others

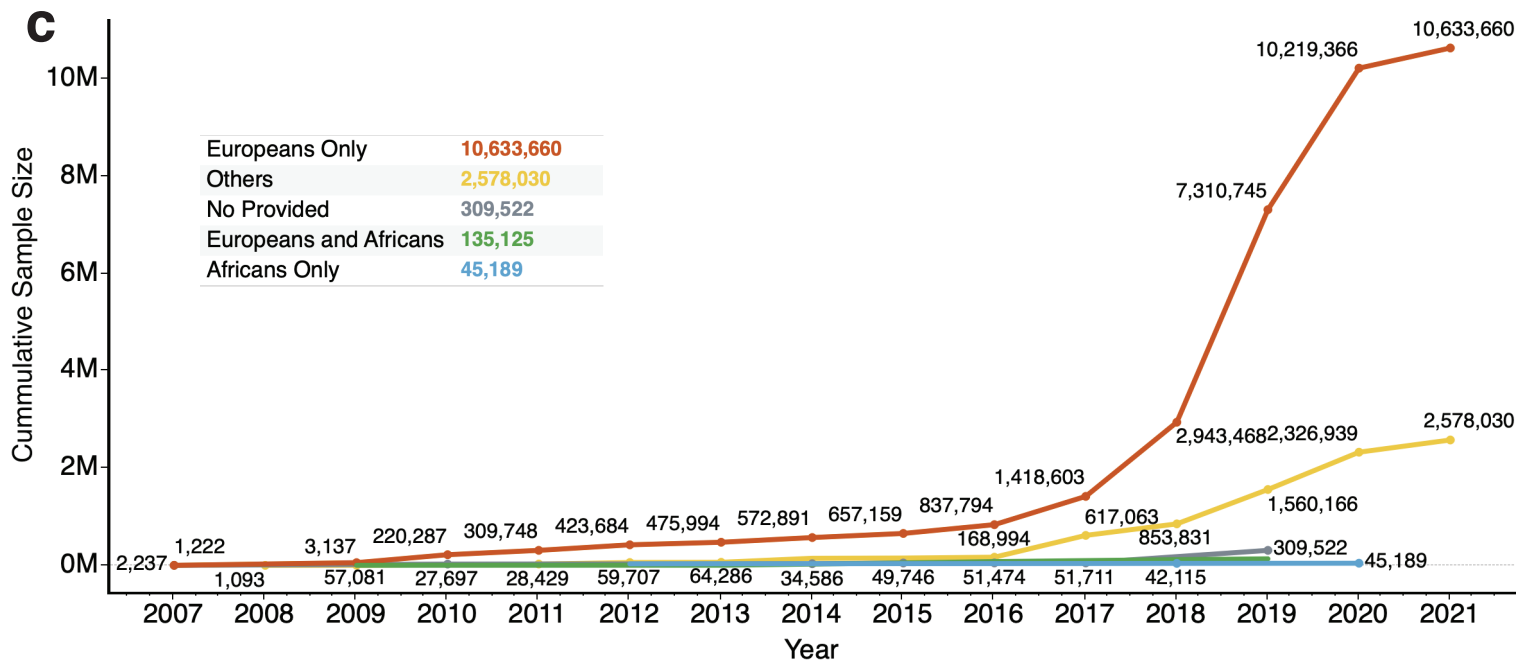

Figure 5: Studies in the GWAS catalogue of pulmonary function and lung phenotypes. (a) The plot of the running sum of GWAS studies reported from 2007 to 2021. The colours show details about the race/ancestry groups: 
medRxiv preprint doi: https://doi.org/10.1101/2022.01.07.22268836; this version posted January 8,2022 . The copyright holder for this preprint (which was not certified by peer review) is the author/funder, who has granted medRxiv a license to display the preprint in perpetuity.

It is made available under a CC-BY-NC 4.0 International license .

Africans only, Europeans only, Europeans and Africans, Others, and those for which the race/ancestry group is "Not provided". (b) The total number of GWAS studies reported for each combination of race/ancestry group. The colours show details about race/ancestry group. (c) The trend of the cumulative sum of participants (on the $y$-axis) of studies from 2007 to 2021. The colours show details about the race/ancestry groups. The marks are labelled by the cumulative sum of participants. The figure insert shows the total number of participants race/ancestry group.

\section{Discussion}

We analysed variations in pulmonary function and the associated genetic variants among individuals of African and European ancestry in the UK Biobank. Here, we report differences in FEV1, FVC, and PEF parameters among Africans and Europeans. Previous studies have examined the pulmonary function parameters between Africans and Europeans, with most reporting the differences we observed 3,36-38. However, there has been no explanation for the genetic basis of these observed differences.

Here, we showed that the SNPs associated with pulmonary function were different between Europeans and Africans. Others have reported that the genetic variants associated with various phenotypes may differ among individuals of various ancestry origins $^{39-42}$. This was confirmed by our findings that different variants might be associated with pulmonary function among Africans and Europeans. Despite this observed difference between the two ancestral groups, we are also cognisant that the number of individuals of African ancestry represented in the UK Biobank is much lower than that of Europeans. The smaller sample size of Africans may have resulted in us missing some of the associated SNPs common among the groups ${ }^{43,44}$. It would be interesting to evaluate our findings based on a larger sample of individuals of African ancestry.

Given that the frequency of SNPs, primarily those we found associated with pulmonary function, varies between Africans and Europeans, it is apparent why different variants are associated with these traits ${ }^{43}$. For example, we found that rs 12925700 is approximately 21 times more frequent, and rs 11205303 is 14 times more frequent in Europeans than Africans, and both SNPs are reported elsewhere ${ }^{45,46}$ and here as being associated with pulmonary function in Europeans. Furthermore, the frequency of genetic variants among individuals of a particular ancestry affects the penetrance of disease and phenotype associated with the alternate alleles ${ }^{43,47-50}$. Non-alcoholic fatty liver disease ${ }^{51}$, serum uric acid levels ${ }^{52}$, white blood cell count ${ }^{53}$, fatty acid desaturases ${ }^{54}$, and other phenotypes ${ }^{55-57}$ are associated with different alleles among Africans and Europeans. These alleles are sometimes located on the same gene, but their frequencies vary between ancestral groups.

Our enrichment analyses demonstrated a link between the significant SNPs and GWAS catalogue terms associated with pulmonary function in Europeans, with several of the results showing plausible biological mechanisms. Whereas it was apparent the significantly enriched terms in Europeans were mainly associated with 
medRxiv preprint doi: https://doi.org/10.1101/2022.01.07.22268836; this version posted January 8, 2022. The copyright holder for this preprint (which was not certified by peer review) is the author/funder, who has granted medRxiv a license to display the preprint in It is made available under a CC-BY-NC 4.0 International license.

pulmonary function and related phenotypes (Figure 3), we found that the top-ranking terms among SNPs of Africans are not related to pulmonary function. Overall, these results suggest that we need a larger sample size of Africans to identify the variants that modify pulmonary function.

We also showed that genetic association studies of pulmonary function and pulmonary physiology and pathology are significantly biased toward individuals of European ancestry. Even in cases where individuals of African ancestry are included in the studies or studied separately, the number of participants is fewer than those of European ancestry. Furthermore, the trend shows that this gap vis-à-vis how Africans and Europeans are studied has widened over the last few years (see Figure 5).

In summary, we have revealed the extent of variations between Africans and Europeans in the pulmonary function parameters; FEV1, FVC and PEF. In addition, we have identified the different genetic variants associated with pulmonary function among individuals of African and European ancestry. Our integrative analysis of the causal genetic variants, together with the GWAS phenotypes and diseases associated with the genes in which the variants fall, indicate that the significant SNPs are associated with pulmonary function and related phenotypes in Europeans. Therefore, it is apparent that more genetic association studies focused on individuals of African ancestry are required to identify and validate additional causal variants of these traits and other diseases.

\section{Methods}

We analysed a UK Biobank ${ }^{11}$ dataset of 383,471 European (designated as White, British, Irish, and "any other White background") and 5,978 African ancestries. The demographics of the UK Biobank participants are extensively described elsewhere ${ }^{11,58}$. The data elements that we analysed include genotyping array data of imputed SNPs, anthropometric measurements, and pulmonary function parameters, FVC, FEV1 and PEF.

\section{Comparison of pulmonary function parameters in Europeans and Africans}

We compare the mean values of the pulmonary function parameter FVC, FEV1 and PEF between 383,471 Europeans and 5,978 Africans using the Welch t-test. Furthermore, to evaluate how FVC, FEV1, PEF, and FEV1/FVC values vary with the participant's body mass index, height, and age, we calculated the $10^{\text {th }}$ percentile bins of each anthropometric measurement and visualised the trend using error bars plotted for each percentile.

\section{Genome-wide identification of genetic variants and associations}

The methods applied for genotyping of participants in the UK Biobank are reported elsewhere ${ }^{11,58}$. We obtained the GWAS summary statistics computed by the UK 
medRxiv preprint doi: https://doi.org/10.1101/2022.01.07.22268836; this version posted January 8, 2022. The copyright holder for this preprint (which was not certified by peer review) is the author/funder, who has granted medRxiv a license to display the preprint in perpetuity.

It is made available under a CC-BY-NC 4.0 International license .

Biobank project of each pulmonary function parameter. The methods used to perform the GWA analyses are described elsewhere ${ }^{59}$. Briefly, the GWAS was performed for the pulmonary function phenotypes and ancestry groups using the Scalable and Accurate Implementation of GEneralized mixed model approach ${ }^{60}$, using a linear or mixed logistic model including a kinship matrix as a random effect and covariates as fixed effects. The covariates included the participant's age, sex, age multiplied by sex, the square of the age, the square of the age multiplied by the sex, and the first 10 principal components calculated from the genotype datasets. The Manhattan plots were produced in MATLAB using the software described here ${ }^{61}$. Furthermore, the fine mapping of SNPs to identify the most credible causal SNPs within each linkage disequilibrium block conditioning on the lead SNP signal in each locus $\pm 50 \mathrm{~kb}$ was done using the PICS2 software ${ }^{62}$.

\section{Pathways and Enrichment Analyses}

We used NBCl's dbSNP63,64 to ascribe the significant variants associated (suggestive cutoff $p$-value ${ }^{16}$ of $1 \times 10^{-6}$ ) with pulmonary function identified using GWAS to specific genes. Then yielded a list of genes associated with pulmonary function in Europeans or Africans. Finally, using these two gene lists (for Europeans and Africans), we separately performed gene set enrichment analysis ${ }^{65}$ using Enrichr66 to identify the Elsevier pathways ${ }^{66}$, DisGeNET database ${ }^{34}$, Phenotype and Genotype Integrator database, and GWAS catalog ${ }^{21}$ ontology terms that are significantly enriched for (see Supplementary File 3).

\section{GWAS literature, disease phenotypes, and eQTLs}

We retrieved data of the previous GWAS of pulmonary function and pulmonary function related phenotypes from the GWAS catalog 21 . This information was subset into two categories: "pulmonary reported"; for those studies that reported pulmonary function phenotype and "pulmonary associated" for those that reported associations related to pulmonary function related phenotypes (see Supplementary File 4). In addition, we considered variants as reported when the linkage disequilibrium R-square values of the significant variants that we report here are greater than 0.5 in relation to the previously reported variants elsewhere. Furthermore, we obtained information on diseases associated with the genes in which the variants are located from the Pharos database ${ }^{67}$. Finally, information on SNPs that are eQTLs in the lungs was obtained from the GTEx consortium database ${ }^{68}$.

\section{Statistics and Reproducibility}

We performed the statistical analyses in R programming language, MATLAB 2021a and Bash. We used the Welch test, Wilcoxon rank-sum test and the one-way Analysis of Variance to compare continuous measures among groups. All statistical tests were considered significant if the returned two-sided $p$-value was $<0.05$ for single comparisons. The multiple hypotheses tests were corrected by calculating a two-sided 
medRxiv preprint doi: https://doi.org/10.1101/2022.01.07.22268836; this version posted January 8, 2022. The copyright holder for this preprint (which was not certified by peer review) is the author/funder, who has granted medRxiv a license to display the preprint in It is made available under a CC-BY-NC 4.0 International license.

q-value (False Discovery Rate) for each group/comparison using the Benjamini \& Hochberg procedure 69 .

\section{Data Availability}

The datasets that support results presented in this manuscript are available from: the UK Biobank; https://www.ukbiobank.ac.uk and https://pan-ukb-us-east1.s3.amazonaws.com, dbSNP; https://www.ncbi.nlm.nih.gov/snp, and the GWAS catalogue; https://www.ebi.ac.uk/gwas.

\section{Code Availability}

Code to reproduce most of the results and plots is available from the corresponding authors upon reasonable request.

\section{Acknowledgements}

The funding for this project was provided by H3ABioNet, supported by the National Institutes of Health Common Fund under grant number U24HG006941. The content of this publication is solely the authors' responsibility and does not necessarily represent the official views of the National Institutes of Health.

\section{Author Contributions}

M.S., S.E., and N.M conceptualized the study. M.S., N.M., S.E., and J.C. designed the methodology, and M.M. M.S, M.M., J.C., and S.E. performed the formal analysis of the data. M.S., N.M., and S.E., drafted manuscript. Editing and reviewing the manuscript was carried out by M.S., N.M., S.E., J.C., and M.M. Data visualisations were produced by M.S. and S.E.

\section{Competing interests}

The authors declare that they have no competing interests

\section{References}

1. Lange, P. et al. Lung-Function Trajectories Leading to Chronic Obstructive Pulmonary Disease. http://dx.doi.org/10.1056/NEJMoa1411532 373, 111-122 (2015).

2. Reilly, J. J. COPD and Declining FEV 1-Time to Divide and Conquer? (2008). doi:10.1056/NEJMe0807387

3. Braun, L. Race, ethnicity and lung function: A brief history. Can. J. Respir. Ther. CJRT = Rev. Can. la Thérapie Respir. RCTR 51, 99 (2015).

4. Bui, D. S. et al. Childhood predictors of lung function trajectories and future COPD risk: a prospective cohort study from the first to the sixth decade of life. Lancet Respir. Med. 6, 535-544 (2018).

5. Artigas, M. S. et al. Sixteen new lung function signals identified through 1000 Genomes Project reference panel imputation. Nat. Commun. 2015616 , 1-12 
medRxiv preprint doi: https://doi.org/10.1101/2022.01.07.22268836; this version posted January 8, 2022. The copyright holder for this preprint (which was not certified by peer review) is the author/funder, who has granted medRxiv a license to display the preprint in perpetuity.

It is made available under a CC-BY-NC 4.0 International license .

(2015).

6. Loth, D. W. et al. Genome-wide association analysis identifies six new loci associated with forced vital capacity. Nat. Genet. 201446746 , 669-677 (2014).

7. Cho, M. H. et al. Risk loci for chronic obstructive pulmonary disease: a genome-wide association study and meta-analysis. Lancet Respir. Med. 2, 214-225 (2014).

8. Wain, L. V et al. Genome-wide association analyses for lung function and chronic obstructive pulmonary disease identify new loci and potential druggable targets. Nat. Genet. 2017493 49, 416-425 (2017).

9. Hobbs, B. D. et al. Genetic loci associated with chronic obstructive pulmonary disease overlap with loci for lung function and pulmonary fibrosis. Nat. Genet. 2017493 49, 426-432 (2017).

10. Wain, L. V. et al. Novel insights into the genetics of smoking behaviour, lung function, and chronic obstructive pulmonary disease (UK BiLEVE): a genetic association study in UK Biobank. Lancet Respir. Med. 3, 769-781 (2015).

11. Bycroft, C. et al. The UK Biobank resource with deep phenotyping and genomic data. Nat. 20185627726 562, 203-209 (2018).

12. Buchman, A. S. et al. Pulmonary function, muscle strength and mortality in old age. Mech. Ageing Dev. 129, 625-631 (2008).

13. Shapira, N. et al. Determinants of pulmonary function in patients undergoing coronary bypass operations. Ann. Thorac. Surg. 50, 268-273 (1990).

14. Schoenberg, J. B., Beck, G. J. \& Bouhuys, A. Growth and decay of pulmonary function in healthy blacks and whites. Respir. Physiol. 33, 367-393 (1978).

15. Park, J. E., Chung, J. H., Lee, K. H. \& Shin, K. C. The Effect of Body Composition on Pulmonary Function. Tuberc. Respir. Dis. (Seoul). 72, 433440 (2012).

16. Hammond, R. K. et al. Biological constraints on gwas snps at suggestive significance thresholds reveal additional bmi loci. Elife 10, 1-19 (2021).

17. Baselmans, B. M. L. et al. Multivariate genome-wide analyses of the well-being spectrum. Nat. Genet. 51, 445-451 (2019).

18. Nagel, M., Speed, D., van der Sluis, S. \& Østergaard, S. D. Genome-wide association study of the sensitivity to environmental stress and adversity neuroticism cluster. Acta Psychiatr. Scand. 141, 476-478 (2020).

19. Shrine, N. et al. New genetic signals for lung function highlight pathways and chronic obstructive pulmonary disease associations across multiple ancestries. Nat. Genet. 51, 481-493 (2019).

20. Hatzikotoulas, K. et al. Genome-wide association study of developmental dysplasia of the hip identifies an association with GDF5. Commun. Biol. 1, (2018).

21. Buniello, A. et al. The NHGRI-EBI GWAS Catalog of published genome-wide association studies, targeted arrays and summary statistics 2019. Nucleic Acids Res. 47, D1005-D1012 (2019).

22. Sloan, D. B., Fields, P. D. \& Havird, J. C. Mitonuclear linkage disequilibrium in human populations. Proc. R. Soc. B Biol. Sci. 282, (2015).

23. Mangin, B. et al. Novel measures of linkage disequilibrium that correct the bias due to population structure and relatedness. Hered. 20121083 108, 285-291 (2011). 
medRxiv preprint doi: https://doi.org/10.1101/2022.01.07.22268836; this version posted January 8, 2022. The copyright holder for this preprint (which was not certified by peer review) is the author/funder, who has granted medRxiv a license to display the preprint in perpetuity.

It is made available under a CC-BY-NC 4.0 International license .

24. KE, T., KM, A., A, M., LA, C. \& KK, F. PICS2: Next-generation fine mapping via probabilistic identification of causal SNPs. Bioinformatics (2021). doi:10.1093/BIOINFORMATICS/BTAB122

25. SI, B. et al. Genome-wide meta-analysis identifies 11 new loci for anthropometric traits and provides insights into genetic architecture. Nat. Genet. 45, 501-512 (2013).

26. H, L. A. et al. Hundreds of variants clustered in genomic loci and biological pathways affect human height. Nature 467, 832-838 (2010).

27. RJ, van der V. et al. A novel common variant in DCST2 is associated with length in early life and height in adulthood. Hum. Mol. Genet. 24, 1155-1168 (2015).

28. I, S. et al. Hmga2 is required for canonical WNT signaling during lung development. BMC Biol. 12, (2014).

29. G, K. et al. Leveraging Polygenic Functional Enrichment to Improve GWAS Power. Am. J. Hum. Genet. 104, 65-75 (2019).

30. NM, W. et al. Maternal and fetal genetic effects on birth weight and their relevance to cardio-metabolic risk factors. Nat. Genet. 51, 804-814 (2019).

31. C, H. et al. Genomics of body fat percentage may contribute to sex bias in anorexia nervosa. Am. J. Med. Genet. B. Neuropsychiatr. Genet. 180, 428438 (2019).

32. DB, H. et al. Meta-analyses of genome-wide association studies identify multiple loci associated with pulmonary function. Nat. Genet. 42, 45-52 (2010).

33. W, K. et al. Genome-Wide Gene-by-Smoking Interaction Study of Chronic Obstructive Pulmonary Disease. Am. J. Epidemiol. 190, 875-885 (2021).

34. Piñero, J. et al. The DisGeNET knowledge platform for disease genomics: 2019 update. Nucleic Acids Res. 48, D845-D855 (2020).

35. Ramos, E. M. et al. Phenotype-Genotype Integrator (PheGenl): synthesizing genome-wide association study (GWAS) data with existing genomic resources. Eur. J. Hum. Genet. 2014221 22, 144-147 (2013).

36. Klimentidis, Y. C. et al. Heritability of pulmonary function estimated from pedigree and whole-genome markers. Front. Genet. 0, 174 (2013).

37. Mak, A. C. Y. et al. Lung Function in African American Children with Asthma Is Associated with Novel Regulatory Variants of the KIT Ligand KITLG/SCF and Gene-By-Air-Pollution Interaction. Genetics 215, 869-886 (2020).

38. HARIK-KHAN, R. I., FLEG, J. L., MULLER, D. C. \& WISE, R. A. The Effect of Anthropometric and Socioeconomic Factors on the Racial Difference in Lung Function. https://doi.org/10.1164/ajrccm.164.9.2106075 164, 1647-1654 (2012).

39. Barnes, K. C. Genomewide association studies in allergy and the influence of ethnicity. Curr. Opin. Allergy Clin. Immunol. 10, 427 (2010).

40. Chan, S. L., Jin, S., Loh, M. \& Brunham, L. R. Progress in understanding the genomic basis for adverse drug reactions: a comprehensive review and focus on the role of ethnicity. http://dx.doi.org/10.2217/PGS.15.54 16, 1161-1178 (2015).

41. Ueta, M. et al. Genome-wide association study using the ethnicity-specific Japonica array: identification of new susceptibility loci for cold medicine-related Stevens-Johnson syndrome with severe ocular complications. J. Hum. Genet. 2017624 62, 485-489 (2017). 
medRxiv preprint doi: https://doi.org/10.1101/2022.01.07.22268836; this version posted January 8, 2022. The copyright holder for this preprint (which was not certified by peer review) is the author/funder, who has granted medRxiv a license to display the preprint in It is made available under a CC-BY-NC 4.0 International license.

42. Jorgenson, E. et al. Genetic contributors to variation in alcohol consumption vary by race/ethnicity in a large multi-ethnic genome-wide association study. Mol. Psychiatry 2017229 22, 1359-1367 (2017).

43. Asif, H. et al. GWAS significance thresholds for deep phenotyping studies can depend upon minor allele frequencies and sample size. Mol. Psychiatry 2020 1-8 (2020). doi:10.1038/s41380-020-0670-3

44. Ball, R. D. Designing a GWAS: Power, Sample Size, and Data Structure. Methods Mol. Biol. 1019, 37-98 (2013).

45. SM, L. et al. A genome-wide association study identifies risk loci for spirometric measures among smokers of European and African ancestry. BMC Genet. 16, (2015).

46. M, M. et al. A systematic analysis of protein-altering exonic variants in chronic obstructive pulmonary disease. Am. J. Physiol. Lung Cell. Mol. Physiol. 321, L130-L143 (2021).

47. Emison, E. S. et al. Differential Contributions of Rare and Common, Coding and Noncoding Ret Mutations to Multifactorial Hirschsprung Disease Liability. Am. J. Hum. Genet. 87, 60-74 (2010).

48. Witte, J. S., Visscher, P. M. \& Wray, N. R. The contribution of genetic variants to disease depends on the ruler. Nat. Rev. Genet. $2014151115,765-776$ (2014).

49. Katsanis, N. The continuum of causality in human genetic disorders. Genome Biol. 2016 171 17, 1-5 (2016).

50. Minikel, E. V. et al. Quantifying prion disease penetrance using large population control cohorts. Sci. Transl. Med. 8, (2016).

51. Palmer, N. D. et al. Characterization of european ancestry nonalcoholic fatty liver disease-associated variants in individuals of african and hispanic descent. Hepatology 58, 966-975 (2013).

52. Rule, A. D. et al. Association between SLC2A9 transporter gene variants and uric acid phenotypes in African American and white families. Rheumatology 50, 871-878 (2011).

53. Reiner, A. P. et al. Genome-Wide Association Study of White Blood Cell Count in 16,388 African Americans: the Continental Origins and Genetic Epidemiology Network (COGENT). PLOS Genet. 7, e1002108 (2011).

54. Buckley, M. T. et al. Selection in Europeans on Fatty Acid Desaturases Associated with Dietary Changes. Mol. Biol. Evol. 34, 1307-1318 (2017).

55. Batai, K. et al. Common vitamin D pathway gene variants reveal contrasting effects on serum vitamin D levels in African Americans and European Americans. Hum. Genet. 2014 13311 133, 1395-1405 (2014).

56. Mathias, R. A. et al. A combined genome-wide linkage and association approach to find susceptibility loci for platelet function phenotypes in European American and African American families with coronary artery disease. BMC Med. Genomics 201031 3, 1-11 (2010).

57. Larkin, E. K. et al. A Candidate Gene Study of Obstructive Sleep Apnea in European Americans and African Americans.

https://doi.org/10.1164/rccm.201002-01920C 182, 947-953 (2012).

58. Bycroft, C. et al. Genome-wide genetic data on $~ 500,000$ UK Biobank participants. bioRxiv 166298 (2017). doi:10.1101/166298

59. Team, P.-U. Quality Control (QC) I Pan UKBB. Available at: https://pan- 
medRxiv preprint doi: https://doi.org/10.1101/2022.01.07.22268836; this version posted January 8, 2022. The copyright holder for this preprint (which was not certified by peer review) is the author/funder, who has granted medRxiv a license to display the preprint in It is made available under a CC-BY-NC 4.0 International license.

dev.ukbb.broadinstitute.org/docs/qc/index.html. (Accessed: 7th November 2021)

60. Zhou, W. et al. Efficiently controlling for case-control imbalance and sample relatedness in large-scale genetic association studies. Nat. Genet. 2018509 50, 1335-1341 (2018).

61. Green, H. Manhattan Plots for visualisation of GWAS results - File Exchange MATLAB Central. Available at:

https://www.mathworks.com/matlabcentral/fileexchange/69549-manhattanplots-for-visualisation-of-gwas-results?s_tid=srchtitle. (Accessed: 4th September 2021)

62. Taylor, K. E., Ansel, K. M., Marson, A., Criswell, L. A. \& Farh, K. K.-H. PICS2: next-generation fine mapping via probabilistic identification of causal SNPs. Bioinformatics (2021). doi:10.1093/BIOINFORMATICS/BTAB122

63. Sayers, E. W. et al. Database resources of the National Center for Biotechnology Information. Nucleic Acids Res. 49, D10 (2021).

64. Pruitt, K. D., Tatusova, T., Brown, G. R. \& Maglott, D. R. NCBI Reference Sequences (RefSeq): current status, new features and genome annotation policy. Nucleic Acids Res. 40, D130-D135 (2012).

65. Subramanian, A. et al. Gene set enrichment analysis: a knowledge-based approach for interpreting genome-wide expression profiles. Proc. Natl. Acad. Sci. U. S. A. 102, 15545-50 (2005).

66. Kuleshov, M. V. et al. Enrichr: a comprehensive gene set enrichment analysis web server 2016 update. Nucleic Acids Res. 44, W90-W97 (2016).

67. Nguyen, D.-T. et al. Pharos: Collating protein information to shed light on the druggable genome. Nucleic Acids Res. 45, D995-D1002 (2017).

68. Ardlie, K. G. et al. The Genotype-Tissue Expression (GTEx) pilot analysis: Multitissue gene regulation in humans. Science (80-. ). 348, 648-660 (2015).

69. Benjamini, Y. Discovering the false discovery rate. J. R. Stat. Soc. Ser. B (Statistical Methodol. 72, 405-416 (2010). 